\title{
Risk Factors for Progression of Degenerative Aortic Valve Disease in the Japanese \\ - The Japanese Aortic Stenosis Study (JASS) Prospective Analysis -
}

Kazuhiro Yamamoto, MD; Hideya Yamamoto, MD; Masaaki Takeuchi, MD; Akira Kisanuki, MD; Takashi Akasaka, MD; Nobuyuki Ohte, MD; Yutaka Hirano, MD; Kiyoshi Yoshida, MD; Satoshi Nakatani, MD; Yasuharu Takeda, MD; Takashi Sozu, PhD; Tohru Masuyama, MD

Background: Because of ethnic difference in the risk of degenerative aortic valve disease (DAVD), risk factors should be clarified in each race to establish prophylactic strategies for severe aortic valve stenosis (AS).

Methods and Results: This study prospectively followed 359 Japanese subjects with DAVD and age $\geq 50$ years for 3 years. As both patients with peak aortic transvalvular flow velocity $\geq 2 \mathrm{~m} / \mathrm{s}$ and $<2 \mathrm{~m} / \mathrm{s}$ were enrolled, subgroup analysis was also conducted. Most patients were under treatment for their comorbidities. The use of warfarin, but none of the traditional risk factors for atherosclerosis, was related to greater reduction in aortic valve area indexed to body surface area (iAVA). In patients with peak aortic transvalvular flow velocity $<2 \mathrm{~m} / \mathrm{s}$, the use of an angiotensinreceptor blocker (ARB) was associated with less decrease in iAVA. In patients with peak velocity $\geq 2 \mathrm{~m} / \mathrm{s}$, changes in iAVA were not related to any baseline characteristics, but peak velocity was less increased under treatment with an angiotensin-converting enzyme inhibitor (ACEI).

Conclusions: In Japanese, the use of warfarin may exacerbate DAVD, and augmented management of atherosclerotic risk factors beyond the recommendations in the current guidelines is unlikely to exert additional benefit. The prescription of ARB for DAVD patients before the development of AS or ACEI after the development of AS may be useful. (Circ J 2015; 79: 2050-2057)

Key Words: Angiotensin-converting enzyme inhibitor; Angiotensin-receptor blocker; Aortic valve; Degeneration; Warfarin

$\mathbf{T}$ he prevalence of aortic valve stenosis (AS) increases with aging, ${ }^{1}$ and the number of patients who undergo aortic valve replacement (AVR) has risen in developed countries. ${ }^{2}$ Consequently, the number of surgical procedures for patients $>75$ years old has grown. ${ }^{3}$ Postoperative mortality after AVR declined in the 1990s, but has not necessarily changed thereafter. ${ }^{3}$

\section{Editorial p 1908}

Degenerative aortic valve disease (DAVD) is the most common cause of AS, particularly in elderly subjects. ${ }^{4}$ The prevalence of AS patients with high operative risks is increased among the elderly and therefore, $73.5 \%$ of octogenarian

Received May 7, 2015; revised manuscript received May 29, 2015; accepted June 10, 2015; released online July 2, 2015 Time for primary review: 17 days

Division of Cardiovascular Medicine, Endocrinology and Metabolism, Department of Molecular Medicine and Therapeutics, Faculty of Medicine, Tottori University, Yonago (K. Yamamoto); Department of Cardiovascular Medicine, Osaka University Graduate School of Medicine, Suita (K. Yamamoto, Y.T.); Department of Cardiovascular Medicine, Hiroshima University Graduate School of Biomedical and Health Sciences, Hiroshima (H.Y.); Department of Laboratory and Transfusion Medicine, School of Medicine, University of Occupational and Environmental Health, Kitakyushu (M.T.); School of Health Sciences, Kagoshima University, Kagoshima (A.K.); Department of Cardiovascular Medicine, Wakayama Medical University, Wakayama (T.A.); Department of Cardio-Renal Medicine and Hypertension, Nagoya City University Graduate School of Medical Sciences, Nagoya (N.O.); Division of Central Clinical Laboratory, Kinki University Hospital, Osakasayama (Y.H.); Department of Cardiology, Kawasaki Medical School, Kurashiki (K. Yoshida); Department of Health Sciences, Division of Functional Diagnostics, Osaka University Graduate School of Medicine, Suita (S.N.); Department of Management Science, Faculty of Engineering, Tokyo University of Science, Tokyo (T.S.); and Cardiovascular Division, Department of Internal Medicine, Hyogo College of Medicine, Nishinomiya (T.M.), Japan

Mailing address: Kazuhiro Yamamoto, MD, Division of Cardiovascular Medicine, Endocrinology and Metabolism, Department of Molecular Medicine and Therapeutics, Faculty of Medicine, Tottori University, 86 Nishi-cho, Yonago 683-8503, Japan. E-mail: ykazuhiro@med.tottori-u.ac.jp

ISSN-1346-9843 doi:10.1253/circj.CJ-15-0499

All rights are reserved to the Japanese Circulation Society. For permissions, please e-mail: cj@j-circ.or.jp 
patients with severe AS do not undergo AVR. ${ }^{5}$ Recently, in many countries, as well as Japan, transcatheter aortic valve replacement (TAVR) has become available as a procedure suitable for AS patients with high operative risks. ${ }^{6,7}$ However, it does not necessarily reduce the mortality as compared with conventional surgical AVR. ${ }^{8,9}$ Prevention of progression to severe AS may be ideal rather than invasive intervention at the advanced stage of severe $\mathrm{AS}$, and it is valuable to identify the risk factors of progression.

Clinical studies report that the risk factors of DAVD are similar to those of atherosclerosis more than a decade ago. ${ }^{10,11}$ However, recent studies have concluded that risk factors for atherosclerosis, such as hypertension and diabetes mellitus, are not necessarily identified as those for AS. ${ }^{12,13}$ Clinical trials failed to show the beneficial effects of lipid-lowering therapy in AS patients, even though ischemic cardiovascular events were reduced in the same subjects. ${ }^{14}$ In addition, ethnic differences in the risk for developing AS are likely present. ${ }^{12,15}$ To establish a preventive strategy, identification of risk factors in each race and in the current era is required.

The aim of the Japanese Aortic Stenosis Study (JASS), a multicenter, hospital-based observational study that consists of retrospective and prospective studies, is to investigate the risk factors for progression of DAVD in Japanese subjects. The JASS Retrospective Analysis retrospectively assessed the risk factors with qualitative assessment of DAVD. ${ }^{16}$ In the current JASS Prospective Analysis, risk factors were prospectively assessed with quantitative evaluation of DAVD.

\section{Methods}

\section{Subjects}

The JASS Prospective Analysis enrolled 359 Japanese subjects who met the following criteria: (1) 50 years old or more; (2) markedly increased reflectivity (calcification) of any aortic valve leaflet or peak aortic transvalvular flow velocity of at least $2 \mathrm{~m} / \mathrm{s}$ on echocardiography performed between 2007 and 2010; (3) agreement to participate in this study, and (4) to undergo annual echocardiography for 3 years. Subjects with rheumatic valvular disease or who had undergone AVR were excluded. The planned maximum follow-up period for each patient was 3 years, and Doppler echocardiography and blood sampling were conducted at study entry and annually thereafter. Phlebotomy was performed in the fasting or non-fasting state. The estimated glomerular filtration rate was calculated using a formula for the Japanese. ${ }^{17}$

This study was conducted in accordance with the principles stated in the Declaration of Helsinki and conforms with the guiding principles of the Ministry of Health, Labour and Welfare, Japan. The study was approved by the local ethics committee of each participating institution, and written informed consent was given by all patients before entry to the study. This study has been registered at http://www.umin.ac.jp/ctr/ listj/ (UMIN000000707).

\section{Echocardiography and Assessment of the Progression of DAVD}

Doppler echocardiography was conducted using commercially available echocardiographic machines as previously described. ${ }^{16}$ In the routine echocardiographic examination, measurements were conducted on-line. Left ventricular mass (LVM) was calculated following a formula derived from data compiled by the American Society of Echocardiography, ${ }^{18}$ and the LVM index was calculated as a ratio of LVM to body surface area (BSA). Using the continuity equation, aortic valve area (AVA) was calculated as previously described, ${ }^{19}$ and was indexed to BSA (iAVA). We calculated the annualized changes in iAVA $\left(\triangle \mathrm{iAVA}, \mathrm{cm}^{2} \cdot \mathrm{m}^{-2} \cdot \mathrm{year}^{-1}\right)$ to assess the progression of DAVD as follows:

\section{(iAVA at final measurement-iAVA at study entry)} Duration of follow-up.

Because echocardiography may not be sensitive enough to reveal the changes in AVA in patients with a small AVA, we calculated the annualized changes in peak aortic transvalvular flow velocity as another marker of the progression of DAVD in patients with $\mathrm{AS}$ as follows:

$\underline{\text { (Peak velocity at final measurement-peak velocity at study entry) }}$ Duration of follow-up.

AS was defined as peak aortic transvalvular flow velocity $\geq 2 \mathrm{~m} / \mathrm{s}^{12,20-22}$

In cases where the 3-year follow-up was not achieved, the latest data were utilized.

\section{Statistical Analysis}

Continuous data are summarized as means and standard deviations, whereas categorical variables were summarized as counts and percentages. To determine the association between progression of DAVD and variables at baseline, the scatter plot was used to assess the linear correlation for continuous variables, and Student's t-test (or 1-way analysis of variance) was used for categorical data. The means between groups were compared by Student's t-test.

Our previous retrospective study suggested that risk factors for the progression of DAVD differ according to disease stage. ${ }^{16}$ Therefore, in addition to analysis of all study subjects, subgroup analysis was conducted following the division of 359 subjects into 2 groups according to the degree of DAVD on baseline echocardiography. The group without AS comprised subjects with peak aortic transvalvular flow velocity $<2 \mathrm{~m} / \mathrm{s}$ at baseline $(\mathrm{n}=150)$. The group with AS comprised subjects with peak aortic transvalvular flow velocity $\geq 2 \mathrm{~m} / \mathrm{s}$ $(n=209)$; 6 patients had a bicuspid aortic valve, but all met the criteria for AS and so were included in the group with AS.

All $\mathrm{P}$ values were 2 -sided, and $\mathrm{P}<0.05$ was considered statistically significant. All statistical analyses were performed with SAS 9.3 (SAS Institute, Inc, Cary, NC, USA).

\section{Results}

\section{Subjects Characteristics}

Baseline characteristics are listed in Tables 1-3. In each table, data of all subjects $(n=359)$, data of the group without AS (peak aortic transvalvular flow velocity $<2 \mathrm{~m} / \mathrm{s}, \mathrm{n}=150$ ), and data of the group with AS (peak aortic transvalvular flow velocity $\geq 2 \mathrm{~m} / \mathrm{s}, \mathrm{n}=209$ ) are shown. Most patients were under treatment for their comorbidities.

\section{Risk Factors for Progression of DAVD}

The mean follow-up period was 2.4 years, and $67.7 \%$ of the study subjects were followed up for 3 years. In all subjects, there was no relation of $\triangle \mathrm{iAVA}$ with any baseline characteristic listed in Tables 1-3 except for the use of warfarin or $\beta$-blocker (Table 4). The use of warfarin or $\beta$-blocker was associated with the greater reduction of iAVA (Table 5). There was no significant difference in iAVA at baseline between patients with and without prescription of warfarin (1.26 \pm 0.49 vs. $\left.1.15 \pm 0.46 \mathrm{~cm}^{2} / \mathrm{m}^{2}, \mathrm{P}=0.118\right)$. Peak aortic transvalvular flow velocity at baseline was slightly but significantly higher 


\begin{tabular}{|c|c|c|c|}
\hline & All & Without AS & With AS \\
\hline$n$ & 359 & 150 & 209 \\
\hline Age (years) & $73.6 \pm 8.1$ & $72.3 \pm 7.7$ & $74.6 \pm 8.2$ \\
\hline Male (\%) & 46.0 & 51.3 & 42.1 \\
\hline Body mass index $\left(\mathrm{kg} / \mathrm{m}^{2}\right)$ & $22.9 \pm 3.5$ & $23.2 \pm 3.5$ & $22.7 \pm 3.5$ \\
\hline Waist circumference $(\mathrm{cm})$ & $84.5 \pm 11.0$ & $85.6 \pm 9.9$ & $83.5 \pm 11.8$ \\
\hline Systolic BP (mmHg) & $134 \pm 18$ & $132 \pm 17$ & $136 \pm 18$ \\
\hline Diastolic BP (mmHg) & $73 \pm 11$ & $73 \pm 10$ & $73 \pm 11$ \\
\hline Heart rate (beats/min) & $68 \pm 11$ & $66 \pm 12$ & $69 \pm 11$ \\
\hline Prevalence of $\mathrm{AF}(\%)$ & 9.2 & 11.3 & 7.7 \\
\hline History of smoking (\%) & 35.4 & 43.3 & 29.7 \\
\hline \multicolumn{4}{|l|}{ Comorbidity (\%) } \\
\hline Hypertension & 78.0 & 82.0 & 75.1 \\
\hline Diabetes mellitus & 29.5 & 30.7 & 28.7 \\
\hline Dyslipidemia & 54.6 & 65.3 & 46.9 \\
\hline Coronary artery disease & 33.4 & 43.3 & 26.3 \\
\hline Cerebrovascular disease & 10.0 & 10.0 & 10.1 \\
\hline Renal insufficiency & 22.3 & 20.0 & 23.9 \\
\hline Hemodialysis & 7.5 & 3.3 & 10.5 \\
\hline \multicolumn{4}{|l|}{ NYHA functional class (\%) } \\
\hline I & 57.4 & 65.3 & 51.7 \\
\hline II & 30.9 & 23.3 & 36.4 \\
\hline III & 9.5 & 8.7 & 10.1 \\
\hline IV & 0 & 0 & 0 \\
\hline \multicolumn{4}{|l|}{ Medications (\%) } \\
\hline ACEI & 18.7 & 26.7 & 12.9 \\
\hline ARB & 46.8 & 46.0 & 47.4 \\
\hline$\beta$-blocker & 31.5 & 42.0 & 23.9 \\
\hline Calcium-channel blocker & 54.0 & 54.7 & 53.6 \\
\hline Mineralocorticoid receptor blocker & 6.7 & 7.3 & 6.2 \\
\hline Nonpotassium-sparing diuretics & 21.2 & 18.0 & 23.4 \\
\hline Antiplatelet agents & 43.5 & 46.0 & 41.6 \\
\hline Warfarin & 16.4 & 22.7 & 12.0 \\
\hline Statins & 40.1 & 48.7 & 34.0 \\
\hline Oral hypoglycemic medications & 15.0 & 12.7 & 16.8 \\
\hline Insulin & 6.7 & 8.0 & 5.7 \\
\hline
\end{tabular}

ACEI, angiotensin-converting enzyme inhibitor; AF, atrial fibrillation; ARB, angiotensin-receptor blocker; AS, aortic valve stenosis; BP, blood pressure; NYHA, New York Heart Association.

in patients not taking warfarin than in those taking the drug ( $2.36 \pm 0.96$ vs. $2.08 \pm 0.83 \mathrm{~m} / \mathrm{s}, \mathrm{P}=0.043)$. At baseline, iAVA was larger and peak aortic transvalvular flow velocity lower in patients taking a $\beta$-blocker than in those not (iAVA: $1.27 \pm 0.48$ vs. $1.12 \pm 0.45 \mathrm{~cm}^{2} / \mathrm{m}^{2}, \mathrm{P}=0.007$, peak velocity: $2.01 \pm 0.84$ vs. $2.45 \pm 0.96 \mathrm{~m} / \mathrm{s}, \mathrm{p}<0.001)$. In contrast, risk factors for atherosclerosis such as diabetes mellitus, dyslipidemia or hypertension were not related to progression of DAVD.

The subgroup analysis showed that the use of an ARB was associated with less decrease in IAVA in the group without AS (Tables 4,5), although iAVA at baseline was significantly smaller in patients treated with than without an ARB $\left(1.51 \pm 0.34\right.$ vs. $\left.1.63 \pm 0.31 \mathrm{~cm}^{2} / \mathrm{m}^{2}, \mathrm{P}=0.032\right)$. Peak aortic transvalvular flow velocity at baseline was not different between the 2 groups $(1.52 \pm 0.27$ vs. $1.49 \pm 0.28 \mathrm{~m} / \mathrm{s}, \mathrm{P}=0.587)$. In the group with $\mathrm{AS}$, none of the baseline characteristics listed in Tables 1-3 were related to $\triangle \mathrm{iAVA}$, but the use of an angiotensin-converting enzyme inhibitor (ACEI) was associated with less increase in peak aortic transvalvular flow velocity $\left(-0.03 \mathrm{~m} \cdot \mathrm{s}^{-1} \cdot\right.$ year $^{-1}$ in $\mathrm{ACEI}(+)$ vs. $0.11 \mathrm{~m} \cdot \mathrm{s}^{-1} \cdot$ year $^{-1}$ in $\mathrm{ACEI}(-), \mathrm{P}=0.025)$. There was no significant difference in iAVA or peak velocity at baseline between patients treated

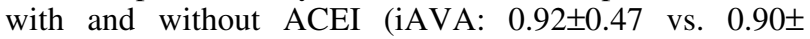
$0.29 \mathrm{~cm}^{2} / \mathrm{m}^{2}, \mathrm{P}=0.771$, peak velocity: $2.91 \pm 1.02$ vs. $2.90 \pm$ $0.79 \mathrm{~m} / \mathrm{s}, \mathrm{P}=0.935)$. The other factors were not related to changes in peak velocity.

\section{Discussion}

The JASS Prospective Analysis demonstrated that none of the traditional risk factors for atherosclerosis was related to progression of DAVD in these Japanese subjects. In all of the study subjects, the use of warfarin or $\beta$-blocker was associated with progression of DAVD. The prescription of an ARB before the development of AS and that of an ACEI after the development of AS was related to slowed progression of DAVD.

The Cardiovascular Health Study demonstrated an agree- 


\begin{tabular}{|c|c|c|c|}
\hline & All & Without AS & With AS \\
\hline Left atrial dimension $(\mathrm{mm})$ & $41 \pm 7$ & $40 \pm 7$ & $41 \pm 7$ \\
\hline LV end-diastolic dimension (mm) & $47 \pm 6$ & $48 \pm 6$ & $46 \pm 6$ \\
\hline LV end-systolic dimension (mm) & $29 \pm 7$ & $30 \pm 7$ & $28 \pm 6$ \\
\hline Ejection fraction (\%) & $65 \pm 12$ & $64 \pm 13$ & $66 \pm 11$ \\
\hline LV mass index $\left(\mathrm{g} / \mathrm{m}^{2}\right)$ & $109.9 \pm 33.0$ & $98.4 \pm 29.2$ & $118.1 \pm 33.2$ \\
\hline Relative wall thickness & $0.43 \pm 0.11$ & $0.39 \pm 0.09$ & $0.46 \pm 0.12$ \\
\hline $\operatorname{AVA}\left(\mathrm{cm}^{2}\right)$ & $1.8 \pm 0.8$ & $2.5 \pm 0.6$ & $1.4 \pm 0.5$ \\
\hline $\mathrm{i} A V A\left(\mathrm{~cm}^{2} / \mathrm{m}^{2}\right)$ & $1.17 \pm 0.46$ & $1.57 \pm 0.33$ & $0.90 \pm 0.32$ \\
\hline Peak aortic transvalvular flow velocity $(\mathrm{m} / \mathrm{s})$ & $2.3 \pm 0.9$ & $1.5 \pm 0.3$ & $2.9 \pm 0.8$ \\
\hline Sinus of Valsalva (mm) & $32.8 \pm 4.4$ & $34.0 \pm 3.9$ & $31.8 \pm 4.4$ \\
\hline Sinotubular junction $(\mathrm{mm})$ & $27.5 \pm 4.3$ & $28.1 \pm 3.8$ & $27.1 \pm 4.6$ \\
\hline Prevalence of aortic annular calcification (\%) & 58.5 & 38.0 & 73.2 \\
\hline Prevalence of sinotubular junction calcification (\%) & 38.4 & 23.3 & 49.3 \\
\hline \multicolumn{4}{|l|}{ Degree of aortic regurgitation (\%) } \\
\hline 0 & 39.6 & 51.3 & 31.1 \\
\hline 1 & 39.3 & 28.0 & 47.4 \\
\hline II & 17.6 & 16.0 & 18.7 \\
\hline III & 3.1 & 4.7 & 1.9 \\
\hline IV & 0.6 & 0 & 1.0 \\
\hline \multicolumn{4}{|l|}{ Degree of mitral regurgitation (\%) } \\
\hline 0 & 35.7 & 38.0 & 34.0 \\
\hline I & 47.6 & 40.0 & 53.1 \\
\hline II & 14.8 & 20.0 & 11.0 \\
\hline III & 1.4 & 0.7 & 1.9 \\
\hline IV & 0.6 & 1.3 & 0.0 \\
\hline
\end{tabular}

AS, aortic valve stenosis; AVA, aortic valve area; iAVA, AVA indexed to body surface area; LV, left ventricular.

\begin{tabular}{|c|c|c|c|}
\hline & All & Without AS & With AS \\
\hline Hemoglobin (g/dl) & $12.4 \pm 1.8$ & $12.9 \pm 1.7$ & $12.0 \pm 1.8$ \\
\hline White blood cell count $(/ \mu l)$ & $5,863 \pm 1,638$ & $5,938 \pm 1,622$ & $5,808 \pm 1,650$ \\
\hline Platelets $\left(10^{4} / \mu \mathrm{l}\right)$ & $20.2 \pm 6.6$ & $21.0 \pm 6.9$ & $19.5 \pm 6.4$ \\
\hline Serum glucose (mg/dl) & $118 \pm 37$ & $113 \pm 29$ & $121 \pm 42$ \\
\hline HbA1c (JDS) (\%) & $5.8 \pm 0.9$ & $5.8 \pm 1.0$ & $5.7 \pm 0.8$ \\
\hline Total cholesterol (mg/dl) & $188 \pm 36$ & $192 \pm 34$ & $185 \pm 37$ \\
\hline $\mathrm{HDL}-\mathrm{C}(\mathrm{mg} / \mathrm{dl})$ & $56 \pm 16$ & $57 \pm 17$ & $55 \pm 16$ \\
\hline Non-HDL-C (mg/dl) & $133 \pm 32$ & $135 \pm 29$ & $131 \pm 34$ \\
\hline LDL-C (mg/dl) & $109 \pm 29$ & $110 \pm 28$ & $109 \pm 30$ \\
\hline Triglyceride (mg/dl) & $120 \pm 67$ & $123 \pm 60$ & $118 \pm 72$ \\
\hline Creatinine (mg/dl) & $1.5 \pm 2.3$ & $1.2 \pm 1.6$ & $1.8 \pm 2.7$ \\
\hline eGFR $\left(\mathrm{ml} / \mathrm{min} / 1.73 \mathrm{~m}^{2}\right)$ & $61.9 \pm 19.6$ & $62.5 \pm 18.0$ & $61.4 \pm 20.9$ \\
\hline Uric acid (mg/dl) & $5.7 \pm 1.5$ & $5.6 \pm 1.4$ & $5.7 \pm 1.6$ \\
\hline BNP (pg/ml) & $159 \pm 356$ & $119 \pm 259$ & $189 \pm 414$ \\
\hline
\end{tabular}

AS, aortic valve stenosis; BNP, B-type natriuretic peptide; eGFR, estimated glomerular filtration rate; HDL-C, highdensity lipoprotein cholesterol; JDS, Japanese Diabetes Society; LDL-C, low-density lipoprotein cholesterol.

ment of the risks of atherosclerosis and DAVD in the $1990 \mathrm{s.} .^{10}$ The Framingham Offspring Study enrolled study subjects with a mean age of 34 years between 1971 and 1975, followed them for 27 years, and concluded that exposure to multiple atherosclerotic risk factors starting in early to mid-adulthood was associated with aortic valve calcification. ${ }^{23}$ However, adherence to guideline-based treatment has improved in the past 2 decades, and the current and other recent studies have shown that traditional risk factors for atherosclerosis such as hypertension and diabetes mellitus are not associated with progression of DAVD. ${ }^{12,13,16}$ Several clinical studies have reported the absence of benefits of statins against progression of AS. ${ }^{24,25}$ The lack of a beneficial effect of lipid-lowering therapy was observed even when the risk of ischemic heart 


\begin{tabular}{lccc|}
\hline $\begin{array}{l}\text { Table 4. P Value for Association of Medication With } \\
\text { ValiAV Disease }\end{array}$ & All & Without AS & With AS \\
& 0.382 & 0.869 & 0.401 \\
ACEI & 0.396 & 0.039 & 0.564 \\
ARB & 0.042 & 0.013 & 0.274 \\
$\beta$-blocker & 0.799 & 0.953 & 0.676 \\
Calcium-channel blocker & 0.370 & 0.848 & 0.166 \\
Mineralocorticoid receptor blocker & 0.679 & 0.790 & 0.504 \\
Nonpotassium-sparing diuretics & 0.524 & 0.914 & 0.510 \\
Antiplatelet agents & 0.026 & 0.054 & 0.116 \\
Warfarin & 0.409 & 0.339 & 0.763 \\
Statins & 0.553 & 0.692 & 0.669 \\
Oral hypoglycemic medications & 0.730 & 0.713 & 0.309 \\
Insulin & &
\end{tabular}

Abbreviations as in Tables 1,2.

\begin{tabular}{|c|c|c|c|}
\hline & All & Without AS & With AS \\
\hline \multicolumn{4}{|c|}{ ARB } \\
\hline+ & $-0.037 \pm 0.117$ & $-0.004 \pm 0.111$ & $-0.060 \pm 0.117$ \\
\hline - & $-0.047 \pm 0.096$ & $-0.044 \pm 0.104^{\star}$ & $-0.051 \pm 0.089$ \\
\hline \multicolumn{4}{|c|}{$\beta$-blocker } \\
\hline+ & $-0.062 \pm 0.121$ & $-0.054 \pm 0.113$ & $-0.072 \pm 0.132$ \\
\hline - & $-0.034 \pm 0.100^{*}$ & $-0.006 \pm 0.102^{*}$ & $-0.051 \pm 0.095$ \\
\hline \multicolumn{4}{|c|}{ Warfarin } \\
\hline+ & $-0.075 \pm 0.157$ & $-0.063 \pm 0.117$ & $-0.090 \pm 0.197$ \\
\hline- & $-0.036 \pm 0.095^{\star}$ & $-0.016 \pm 0.106^{\star}$ & $-0.051 \pm 0.084$ \\
\hline
\end{tabular}

${ }^{*} \mathrm{P}<0.05$ vs. + . Abbreviations as in Tables 1,2 .

disease was reduced in the same subjects. ${ }^{14}$ In addition, we have to take into account that atherosclerosis and DAVD have different pathophysiology. ${ }^{26-28}$ Although uncontrolled or longterm or early exposure to atherosclerotic risks are likely to contribute to progression of DAVD, additional management of atherosclerotic risk factors beyond that recommended in the current guidelines may not provide any further benefits against progression of DAVD. Our and the previous studies also indicate that it is currently difficult to predict progression of DAVD, and careful, periodic follow-up is required in patients with DAVD regardless of their clinical characteristics. The guidelines have recommended the follow-up strategy for asymptomatic patients with severe AS, but we have to keep in mind the progression of DAVD in a substantial number of elderly subjects without AS. ${ }^{12,29}$ Although echocardiography is the most useful tool to detect progression of DAVD, we have to take health economics into account, and the appropriate interval of echocardiographic examination of patients with DAVD but without severe AS should be discussed in the future. At least, we may be able to recommend routine auscultation to physicians.

The current prospective study demonstrated that the use of warfarin was associated with progression of DAVD, which is at least partly compatible with the results of our previous retrospective study. ${ }^{16}$ Warfarin attenuates the synthesis and function of matrix $\gamma$-carboxyglutamic acid protein, a potent inhibitor of tissue calcification, through its incom- plete $\gamma$-carboxylation by antagonization of vitamin K. ${ }^{30}$ Another possible mechanism of the contribution of warfarin to the progression of DAVD is hemorrhage in the leaflets facilitated by warfarin, because Akahori et al reported a frequent association between intraleaflet hemorrhage and a rapid progression of AS in patients with severe AS. ${ }^{31,32}$ Although the relationship of progression of DAVD to the use of warfarin can be theoretically understandable, it is difficult to explain the relation of $\beta$-blocker to DAVD and further studies are necessary.

In the subgroup without $\mathrm{AS}$, the non-use of ARBs was raised as a risk for progression of DAVD, which is compatible with the results of our previous retrospective study. ${ }^{16} \mathrm{ACE}$, chymase and angiotensin II type 1 receptor are upregulated in the calcified human aortic valve compared with the normal valve, ${ }^{33,34}$ suggesting activation of the angiotensin II-angiotensin-receptor axis in DAVD. AS is associated with enhanced inflammatory changes in the aortic valve in the early stage, but with a 'burnt-out' condition in the late stage. ${ }^{35}$ As the expression of ACE and chymase colocalizes with inflammatory cells,${ }^{34}$ a metabolic response to ARBs may be expected only during active inflammation of the aortic valve and may be small or absent after the reduction of inflammatory activity (ie, after the development of AS).

In patients with peak aortic transvalvular flow velocity $\geq 2 \mathrm{~m} / \mathrm{s}$, no factors were related to $\triangle \mathrm{iAVA}$ in the current study. However, iAVA was significantly smaller in those patients 
than in patients with peak velocity $<2 \mathrm{~m} / \mathrm{s}$ (Table 2 ), and echocardiography may not be sensitive enough to reveal the changes in AVA in patients with a small AVA. Therefore, we also assessed the changes in peak aortic transvalvular flow velocity, and found that the administration of ACEI was associated with less increase in velocity than non-use of ACEIs. This result is compatible with our preliminary study that showed an association of the prescription of ACEI with slow increase of the aortic transvalvular flow velocity in patients with a baseline peak velocity $\geq 2 \mathrm{~m} / \mathrm{s} .{ }^{36}$ O'Brien et al reported that ACEIs attenuate the progression of aortic valve calcification as measured by electron beam computed tomography. ${ }^{37}$ Nadir et al reported in a retrospective, population-based longitudinal cohort study that the use of an ACEI or ARB resulted in improved clinical outcomes for patients with AS, ${ }^{38}$ although it is unclear whether the benefits were exerted through effects on the aortic valve or on LV myocardium exposed to ASinduced pressure overload. In that study, $87 \%$ of the patients in the ACEI/ARB group were treated with an ACEI. In contrast, Rosenhek et al failed to find benefits of ACEI therapy. ${ }^{39}$ These discrepancies may be partly explained by differences in the severity of DAVD among the study subjects. The mean peak aortic transvalvular flow velocity was $2.9 \mathrm{~m} / \mathrm{s}$ in the current study's subjects with a baseline peak velocity $\geq 2 \mathrm{~m} / \mathrm{s}$, $2.4 \mathrm{~m} / \mathrm{s}$ in Wakabayashi's study, $3.3 \mathrm{~m} / \mathrm{s}$ in Nadir's study, and $3.9 \mathrm{~m} / \mathrm{s}$ in Rosenhek's study. Although echocardiographic data were lacking in O'Brien's study, these results suggest that ACEIs exert beneficial effects at a relatively early stage after the development of AS but not at the very advanced stage. Helske et al demonstrated that bradykinin type 1 and 2 receptors were expressed in the aortic valves of patients who underwent AVR. ${ }^{40}$ The type 1 receptor mediates fibrotic changes, and the type 2 receptor exerts antifibrotic effects. The balance of the expression of these receptors may vary according to the disease stage, resulting in the inconsistent effects of ACEIs among patients with AS.

DAVD is common and progressive in elderly subjects, ${ }^{12,29}$ and is related to poor prognosis. ${ }^{41}$ The prevention of its progression may well contribute to improvements in the activities of daily life, morbidity and mortality of the elder population. Advanced DAVD requires AVR, and thus, prevention of the progression of DAVD may have socioeconomic merit through avoidance of AVR. The prevalence of atrial fibrillation increases with aging, ${ }^{42}$ and anticoagulation therapy is suggested by guideline-based treatment in many elder patients with atrial fibrillation to prevent thromboembolic events. ${ }^{43}$ Warfarin has been principally used for anticoagulation therapy; however, the risk of warfarin in promoting calcification of soft tissue has not been widely recognized. Several crosssectional studies have reported the increased ratio of valvular or coronary calcification in patients treated with warfarin..$^{44,45}$ The current study confirmed this phenomenon in a prospective observation. Recently, several new anticoagulants that exert their effects independent of vitamin $\mathrm{K}$ antagonization are available, and their benefits in preventing thromboembolic events are not inferior to that of warfarin. ${ }^{43}$ As warfarininduced calcification is likely promoted in patients with chronic usage or in elderly patients, ${ }^{45}$ the results of the current and previous studies call attention to the use of warfarin in patients with atrial fibrillation, in particular those who need anticoagulation chronically or elderly patients. It is interesting whether ARBs or ACEIs can cancel such effects of warfarin on DAVD, however, the number of the subjects treated with both warfarin and ARB/ACEI was small in the current study, and the ongoing JASS-2 study (UMIN ID; 000003007, https:// upload.umin.ac.jp/cgi-open-bin/ctr/ctr.cgi?function=brows\& action $=$ brows \&type $=$ summary \& recptno $=\mathrm{R} 000003642 \&$ lang uage $=\mathrm{J}$ ) is awaited.

\section{Study Limitations}

First, this was an observational and hospital-based study, and thus the selection of study subjects might be biased. In particular, the baseline characteristics of patients treated with and without each medicine were not comparable. To assess the effects of each medicine on the progression of DAVD, propensity matching is preferable; however, the number of the study subjects was not large enough to adjust their characteristics. In this study, peak aortic transvalvular flow velocity at baseline was lower in patients treated with than without warfarin, and iAVA at baseline was larger in patients treated without than with an ARB. Previous studies showed that progression of AS is more rapid in patients with more severe AS. ${ }^{46,47}$ Thus, lower peak velocity at baseline in patients treated with warfarin or larger iAVA at baseline in patients treated without ARB is unlikely to explain the greater reduction of iAVA in association with the use of warfarin or nonuse of ARBs in this study. Future studies with larger numbers of subjects are required. Second, the duration of exposure to atherosclerotic risk factors such as hypertension and diabetes mellitus was not taken into account, and its effects on progression of DAVD cannot be discussed in this study.

\section{Conclusions}

In a Japanese study, atherosclerotic risk factors were not associated with progression of DAVD. As most patients were under treatment for their comorbidities in this study, the current results suggest that management of risk factors beyond the current guidelines does not provide any additional benefits against progression of DAVD. In DAVD patients, the use of warfarin is likely a risk for progression of DAVD. The prescription of ARBs for DAVD patients before the development of AS or that of ACEIs early after the development of AS may be useful.

\section{Acknowledgments}

This study was supported by grants from the Ministry of Health, Labour and Welfare (Tokyo, Japan), and the Japan Heart Foundation (Tokyo, Japan). The authors gratefully acknowledge the support of the Japanese Circulation Society.

\section{Grant Support}

This study was supported by grants from the Ministry of Health, Labour and Welfare (Tokyo, Japan), and the Japan Heart Foundation (Tokyo, Japan).

\section{Disclosures}

All authors take responsibility for all aspects of the reliability and freedom from bias of the data presented and their discussed interpretation.

$\mathrm{K}$. Yamamoto reports receiving grant support and lecturer's fees from Daiichi Sankyo, Otsuka, Mitsubishi Tanabe, Toa Eiyo, Boehringer Ingelheim, Bristol-Myers Squibb and Sanwa Kagaku Kenkyusho.

M.T. reports receiving grant support and lecturer's fee from MSD.

T.A. reports receiving grant support and lecturer's fees from St. Jude Medical Japan Co, Ltd, Terumo Corporation, and Goodman Co, Ltd, and lecturer's fees from Daiichi Sankyo Co, Ltd, Abbott Vascular Japan Co, Ltd, and Astellas Pharma Inc.

N.O. reports receiving grant support and lecturer's fees from Takeda, Boehringer Ingelheim, Dainihon-Sumitomo, MSD, Daiichi Sankyo, Otsuka, and Kowa.

S.N. is a medical advisor of Edwards Lifesciences Corporation.

T.M. reports receiving grant support and lecturer's fees from St. Jude Medical Japan, Medtronic Japan, Daiichi Sankyo, Takeda, Kowa, 
Mitsubishi Tanabe, Merck Sharp \& Dohme, Johnson \& Johnson, Boston Scientific Japan and Sanwa Kagaku Kenkyusho.

H.Y., A.K., Y.T., Y.H., K. Yoshida, and T.S. report no conflicts of interest.

\section{References}

1. Danielsen R, Aspelund T, Harris TB, Gudnason V. The prevalence of aortic stenosis in the elderly in Iceland and predictions for the coming decades: The AGES-Reykjavik study. Int J Cardiol 2014; 176: $916-922$

2. Barreto-Filho JA, Wang Y, Dodson JA, Desai MM, Sugeng L, Geirsson A, et al. Trends in aortic valve replacement for elderly patients in the United States, 1999-2011. JAMA 2013; 310: 2078 2085.

3. Martinsson A, Li X, Andersson C, Nilsson J, Smith JG, Sundquist $\mathrm{K}$. Temporal trends in incidence and prognosis of aortic stenosis: A nationwide study of the Swedish population. Circulation 2015; 131: 988-994.

4. Iung B, Baron G, Butchart EG, Delahaye F, Gohlke-Bärwolf C, Levang OW, et al. A prospective survey of patients with valvular heart disease in Europe: The Euro Heart Survey on Valvular Heart Disease. Eur Heart J 2003; 24: 1231-1243.

5. Bach DS, Siao D, Girard SE, Duvernoy C, McCallister BD Jr, Gualano SK. Evaluation of patients with severe symptomatic aortic stenosis who do not undergo aortic valve replacement: The potential role of subjectively overestimated operative risk. Circ Cardiovasc Qual Outcomes 2009; 2: 533-539.

6. Maeda K, Kuratani T, Mizote I, Shimamura K, Takeda Y, Torikai K, et al. Early experiences of transcatheter aortic valve replacement in Japan. Circ J 2013; 77: 359-362.

7. Sawa Y, Saito S, Kobayashi J, Niinami H, Kuratani T, Maeda K, et al. First clinical trial of a self-expandable transcatheter heart valve in Japan in patients with symptomatic severe aortic stenosis. Circ J 2014; 78: $1083-1090$.

8. Smith CR, Leon MB, Mack MJ, Miller DC, Moses JW, Svensson LG, et al. Transcatheter versus surgical aortic-valve replacement in high-risk patients. N Engl J Med 2011; 364: 2187-2198.

9. Thyregod HGH, Steinbrüchel DA, Ihlemann N, Nissen H, Kjeldsen BJ, Petursson P, et al. Transcatheter versus surgical aortic valve replacement in patients with severe aortic valve stenosis: One-year results from the all-comers Nordic aortic valve intervention (NOTION) randomized clinical trial. J Am Coll Cardiol 2015; 65: $2184-2194$.

10. Stewart B, Siscovick D, Lind BK, Gardin JM, Gottdiener JS, Smith VE, et al. Clinical factors associated with calcific aortic valve disease: Cardiovascular Health Study. J Am Coll Cardiol 1997; 29: 630-634.

11. Aronow WS, Ahn C, Kronzon I, Goldman ME. Association of coronary risk factors and use of statins with progression of mild valvular aortic stenosis in older persons. Am J Cardiol 2001; 88: 693-695.

12. Novaro GM, Katz R, Aviles RJ, Gottdiener JS, Cushman M, Psaty $\mathrm{BM}$, et al. Clinical factors, but not C-reactive protein, predict progression of calcific aortic-valve disease: The Cardiovascular Health Study. J Am Coll Cardiol 2007; 50: 1992-1999.

13. Monin JL, Lancellotti P, Monchi M, Lim P, Weiss E, Pierard L, et al. Risk score for predicting outcome in patients with asymptomatic aortic stenosis. Circulation 2009; 120: 69-75.

14. Rosseb $\varnothing$ AB, Pedersen TR, Boman K, Brudi P, Chambers JB, Egstrup K, et al. Intensive lipid lowering with simvastatin and ezetimibe in aortic stenosis. N Engl J Med 2008; 359: 1343-1356.

15. Patel DK, Green KD, Fudim M, Harrell FE, Wang TJ, Robbins MA. Racial differences in the prevalence of severe aortic stenosis. $\mathrm{J} \mathrm{Am}$ Heart Assoc 2014; 3: e000879, doi:10.1161/JAHA.114.000879.

16. Yamamoto K, Yamamoto H, Yoshida K, Kisanuki A, Hirano Y, Ohte N, et al. Prognostic factors for progression of early- and latestage calcific aortic valve disease in Japanese: The Japanese Aortic Stenosis Study (JASS) Retrospective Analysis. Hypertens Res 2010; 33: $269-274$.

17. Matsuo S, Imai E, Horio M, Yasuda Y, Tomita K, Nitta K, et al. Revised equations for estimated GFR from serum creatinine in Japan. Am J Kidney Dis 2009; 53: 982-992.

18. Lang RM, Bierig M, Devereux RB, Flachskampf FA, Foster E, Pellikka PA, et al. Recommendations for chamber quantification: A report from the American Society of Echocardiography's guidelines and quantification writing group, developed in conjunction with the European Association of Echocardiography, a branch of the European Society of Cardiology. J Am Soc Echocardiogr 2005; 18: $1440-1463$.

19. Sato K, Seo Y, Ishizu T, Takeuchi M, Izumo M, Suzuki K, et al.
Prognostic value of global longitudinal strain in paradoxical lowflow, low-gradient severe aortic stenosis with preserved ejection fraction. Circ J 2014; 78: 2750-2759.

20. Faggiano P, Antonini-Canterin F, Erlicher A, Romeo C, Cervesato E, Pavan D, et al. Progression of aortic valve sclerosis to aortic stenosis. Am J Cardiol 2003; 91: 99-101.

21. Cosmi JE, Kort S, Tunick PA, Rosenzweig BP, Freedberg RS, Katz ES, et al. The risk of the development of aortic stenosis in patients with benign aortic valve thickening. Arch Intern Med 2002; 162: $2345-2347$.

22. Dichtl W, Alber HF, Feuchtner GM, Hintringer F, Reinthaler M, Bartel T, et al. Prognosis and risk factors in patients with asymptomatic aortic stenosis and their modulation by atorvastatin $(20 \mathrm{mg}) . A m$ J Cardiol 2008; 102: 743-748.

23. Thanassoulis G, Massaro JM, Cury R, Manders E, Benjamin EJ, Vasan RS, et al. Associations of long-term and early adult atherosclerosis risk factors with aortic and mitral valve calcium. J Am Coll Cardiol 2010; 55: 2491-2498.

24. Cowell SJ, Newby DE, Prescott RJ, Bloomfield P, Reid J, Northridge $\mathrm{DB}$, et al. A randomized trial of intensive lipid-lowering therapy in calcific aortic stenosis. N Engl J Med 2005; 352: 2389-2397.

25. Chan KL, Teo K, Dumesnil JG, Ni A, Tam J. Effect of Lipid lowering with rosuvastatin on progression of aortic stenosis: Results of the aortic stenosis progression observation: Measuring effects of rosuvastatin (ASTRONOMER) trial. Circulation 2010; 121: 306-314.

26. O'Brien KD. Pathogenesis of calcific aortic valve disease; a disease process comes of age (and a good deal more). Arterioscler Thromb Vasc Biol 2006; 26: 1721 -1728.

27. Goldbarg SH, Elmariah S, Miller MA, Fuster V. Insights into degenerative aortic valve disease. J Am Coll Cardiol 2007; 50: 1205-1213.

28. Miller JD, Chu Y, Brooks RM, Richenbacher WE, Peña-Silva R, Heistad DD. Dysregulation of antioxidant mechanisms contributes to increased oxidative stress in calcific aortic valvular stenosis in humans. J Am Coll Cardiol 2008; 52: 843-850.

29. Otto CM, Lind BK, Kitzman DW, Gersh BJ, Siscovick DS. Association of aortic-valve sclerosis with cardiovascular mortality and morbidity in the elderly. N Engl J Med 1999; 341: 142-147.

30. Vermeer C. Gamma-carboxyglutamatecontaining proteins and the vitamin K-dependent carboxylase. Biochem J 1990; 266: 625-636.

31. Akahori H, Tsujino T, Naito Y, Matsumoto M, Lee-Kawabata M, Ohyanagi M, et al. Intraleaflet haemorrhage is associated with rapid progression of degenerative aortic valve stenosis. Eur Heart J 2011; 32: $888-896$.

32. Akahori H, Tsujino T, Naito $\mathrm{Y}$, Yoshida C, Lee-Kawabata M, Ohyanagi $\mathrm{M}$, et al. Intraleaflet haemorrhage as a mechanism of rapid progression of stenosis in bicuspid aortic valve. Int J Cardiol 2013; 167: $514-518$.

33. O'Brien KD, Shavelle DM, Caulfield MT, McDonald TO, OlinLewis K, Otto CM, et al. Association of angiotensin-converting enzyme with low-density lipoprotein in aortic valvular lesions and in human plasma. Circulation 2002; 106: 2224-2230.

34. Helske S, Lindstedt KA, Laine $\mathrm{M}$, Mäyränpää $\mathrm{M}$, Werkkala $\mathrm{K}$, Lommi J, et al. Induction of local angiotensin II-producing systems in stenotic aortic valves. J Am Coll Cardiol 2004; 44: 1859-1866.

35. Marincheva-Savcheva G, Subramanian S, Qadir S, Figueroa A, Truong Q, Vijayakumar J, et al. Imaging of the aortic valve using fluorodeoxyglucose positron emission tomography increased valvular fluorodeoxyglucose uptake in aortic stenosis. J Am Coll Cardiol 2011; 57: 2507-2515.

36. Wakabayashi K, Tsujino T, Naito Y, Ezumi A, Lee-Kawabata M, Nakao S, et al. Administration of angiotensin-converting enzyme inhibitors is associated with slow progression of mild aortic stenosis in Japanese patients. Heart Vessels 2011; 26: 252-257.

37. O'Brien KD, Probstfield JL, Caulfield MT, Nasir K, Takasu J, Shavelle DM, et al. Angiotensin-converting enzyme inhibitors and change in aortic valve calcium. Arch Intern Med 2005; 165: $858-$ 862.

38. Nadir MA, Wei L, Elder DH, Libianto R, Lim TK, Pauriah M, et al. Impact of renin-angiotensin system blockade therapy on outcome in aortic stenosis. J Am Coll Cardiol 2011; 58: 570-576.

39. Rosenhek R, Rader F, Loho N, Gabriel H, Heger M, Klaar U, et al. Statins but not angiotensin-converting enzyme inhibitors delay progression of aortic stenosis. Circulation 2004; 110: 1291-1295.

40. Helske S, Laine M, Kupari M, Lommi J, Turto H, Nurmi L, et al. Increased expression of profibrotic neutral endopeptidase and bradykinin type 1 receptors in stenotic aortic valves. Eur Heart J 2007; 28: $1894-1903$

41. Gaibazzi N, Porter TR, Agricola E, Cioffi G, Mazzone C, Lorenzoni $\mathrm{V}$, et al. Prognostic value of echocardiographic calcium score in patients with a clinical indication for stress echocardiography. JACC 
Cardiovasc Imaging 2015; 8: 389-396.

42. Naccarelli GV, Varker H, Lin J, Schulman KL. Increasing prevalence of atrial fibrillation and flutter in the United States. Am J Cardiol 2009; 104: 1534-1539.

43. January CT, Wann LS, Alpert JS, Calkins H, Cigarroa JE, Cleveland JC Jr, et al. 2014 AHA/ACC/HRS guideline for the management of patients with atrial fibrillation: A report of the American College of Cardiology/American Heart Association Task Force on Practice Guidelines and the Heart Rhythm Society. J Am Coll Cardiol 2014; 64: e1-e76, doi:10.1016/j.jacc.2014.03.022.

44. Lerner RG, Aronow WS, Sekhri A, Palaniswamy C, Ahn C, Singh $\mathrm{T}$, et al. Warfarin use and the risk of valvular calcification. J Thromb Haemost 2009; 7: 2023-2027.

45. Weijs B, Blaauw Y, Rennenberg RJ, Schurgers LJ, Timmermans $\mathrm{CC}$, Pison $\mathrm{L}$, et al. Patients using vitamin $\mathrm{K}$ antagonists show increased levels of coronary calcification: An observational study in low-risk atrial fibrillation patients. Eur Heart J 2011; 32: $2555-2562$.

46. Otto CM, Burwash IG, Legget ME, Munt BI, Fujioka M, Healy NL, et al. Prospective study of asymptomatic valvular aortic stenosis: Clinical, echocardiographic, and exercise predictors of outcome. Circulation 1997; 95: 2262-2270.

47. Bahler RC, Desser DR, Finkelhor RS, Brener SJ, Youssefi M. Factors leading to progression of valvular aortic stenosis. Am J Cardiol 1999; 84: 1044-1048.

\section{Appendix}

Participating Institutions and Investigators

Hiroshima University; Yamamoto H, Utsunomiya H; Hyogo College of Medicine; Masuyama T, Tsujino T; Kagoshima University; Kisanuki A, Toyonaga K; Kawasaki Medical School; Yoshida K, Imai K, Kume T; Kinki University; Hirano Y; Nagoya City University; Ohte N, Wakami K; Osaka University; Yamamoto K, Sakata Y, Takeda Y, Tsukamoto Y, Saito Y, Nakatani S; University of Occupational and Environmental Health; Otsuji Y, Takeuchi M; Wakayama Medical University; Akasaka $\mathrm{T}$, Tanimoto $\mathrm{T}$. 